\title{
Study of absorption characteristics of phytoplankton, particles and colored dissolved organic matter in Lake Baikal (July 2018 and September 2019)
}

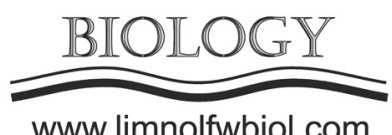

www.limnolfwbiol.com

\author{
Churilova T. ${ }^{1 *}$, Moiseeva N. ${ }^{1}$, Efimova T. ${ }^{1}$, Skorokhod E. ${ }^{1}$, Sorokovikova E. ${ }^{2}$, \\ Belykh O. ${ }^{2}$, Usoltseva M. ${ }^{2}$, Blinov V. ${ }^{2}$, Makarov M. ${ }^{2}$, Gnatovsky R. ${ }^{2}$
}

${ }^{1}$ O.A.Kovalevski Institute of Biology of the Southern Seas, Russian Academy of Sciences, 2 Nakhimov Ave, Sevastopol, 299011, Russia

${ }^{2}$ Limnological Institute, Siberian Branch of the Russian Academy of Sciences, Ulan-Batorskaya Str., 3, Irkutsk, 664033, Russia

\begin{abstract}
Results of two scientific cruises carried out in July 2018 and September 2019 were used for an analysis of variability in spectral bio-optical properties of Lake Baikal. Chlorophyll $a$ concentration, spectral light absorption coefficient of phytoplankton, non-algal particles and colored dissolved organic matter varied in order of magnitude between stations. Vertical distribution of these bio-optical parameters depended on water column stability in euphotic layer. The chlorophyll $a$ profiles were characterized by maximum near the bottom of euphotic zone. In the layer of deep chlorophyll $a$ maximum the phytoplankton absorption spectra had a specific feature - a local maximum at 550-570 $\mathrm{nm}$. It was associated with relative increasing of phycoerythrin containing species in phytoplankton community. The absorption budget at $440 \mathrm{~nm}$ showed that the CDOM was the main optically active component, which provided $\sim 50 \%$ contribution to total absorption on averaged over Lake Baikal surface.
\end{abstract}

Keywords: phytoplankton, chlorophyll $a$, phycoerythrin, light absorption, non-algal particles, colored dissolved organic matter, Lake Baikal.

\section{Introduction}

Operative monitoring of the state of unique ecosystem of Lake Baikal can be realized by remote approach. For correct transformation of satellite data to water quality and productivity indicators the development of regional algorithms is required. Spectral absorption properties of phytoplankton, non-algal particles and colored dissolved organic matter are key parameters in bio-optical algorithms. Aim of the research was to investigate spatial and temporal variability in spectral light absorption coefficients of all optically active substances, their link to chlorophyll $a$.

\section{Methods}

Variability in spectral bio-optical properties of Lake Baikal was investigated in two scientific cruises carried out in July 2018 (RV G.Yu.Vereshagin) and September 2019 (RV G.Titov). Water transparency was assessed based on Secchi disk visibility in July 2018. In September 2019 vertical profiles of temperature, salinity, density, fluorescence (calibrated in dimension of chlorophyll $a$ concentration), and photosynthetically available radiation (PAR) were measured by a JFE
Rinko AAQ-177 water quality probe (Japan). Pigment concentration was measured by spectrophotometric method (Jeffrey and Humphry, 1975). Spectral absorption by particles $\left(a_{p}(\lambda)\right)$ and colored dissolved organic matter $\left(a_{C D O M}(\lambda)\right)$ were measured in line with the NASA protocol (Boss et al., 2018). To separate the phytoplankton pigments light absorption $\left(a_{p h}(\lambda)\right)$ and non-algal pigments absorption $\left(a_{N A P}(\lambda)\right.$ ) from $a_{p}(\lambda)$ the pigments were bleached using $\mathrm{NaClO} 1 \%$ active chloride following the methods of Tassan and Ferrari (1995). For particulate absorption GF/F filters (25 $\mathrm{mm}$ diameter) were used. In calculation of particulate absorption, the b-correction was done in line with Mitchell (1990). To determine CDOM absorption water samples were filtered through $47 \mathrm{~mm}$ diameter $0.2 \mu \mathrm{m}$ nucleopore filters using first $50 \mathrm{ml}$ filtered sample for rinsing. Optical density of the samples particles on the filters and dissolved organic matter were measured with dual-beam spectrophotometer Lambda 35, Perkin Elmer (equipped with integrating sphere) from 350 to $750 \mathrm{~nm}$ and from 250 to $750 \mathrm{~nm}$, correspondingly. Fitting of measured $a_{N A P}(\lambda)$ and $a_{C D O M}(\lambda)$ coefficients to exponential function was done for wavelength domain from 400 to $700 \mathrm{~nm}$ and

*Corresponding author.

E-mail address: tanya.churilova@ibss-ras.ru (Tanya Churilova) 


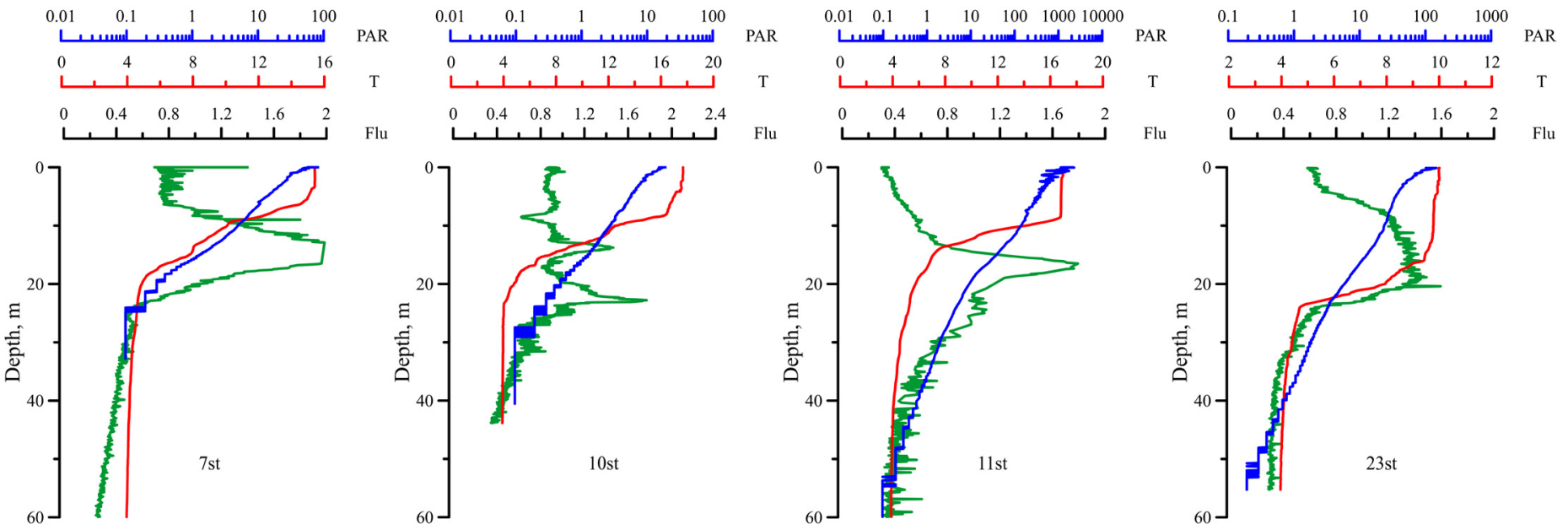

Fig. 1. Vertical profiles of chlorophyll $a$ fluorescence (Flu, green line), temperature $\left(\mathrm{T},{ }^{\circ} \mathrm{C}\right.$, red line), photosynthetic available radiation (PAR, $\mu \mathrm{E} \mathrm{m}^{-2} \mathrm{~s}^{-1}$, blue line) at particular stations in Lake Baikal in September 2019.

from 350 to $500 \mathrm{~nm}$, correspondingly, in accordance with Babin et al. (2003).

\section{Results and discussion}

Spatial variability of chlorophyll $a$ concentration (Chl-a), light absorption coefficient of phytoplankton $\left(a_{p h}(\lambda)\right.$, non-algal particles $\left(a_{\text {NAP }}(\lambda)\right)$ and colored dissolved organic matter $\left(a_{C D O M}(\lambda)\right)$ was rather high (in order and higher).

In surface layer values of Chl- $a$ varied from 0.58 to $5.3 \mathrm{mg} \mathrm{m}^{-3}$ in July 2018 and from 0.90 to $2.7 \mathrm{mg}$ $\mathrm{m}^{-3}$ in September 2019. Vertical distribution of Chl- $a$ was dependent on hydrophysical characteristics, in particular, on temperature stratification of water column (Fig. 1). In situ measured temperature, chlorophyll $a$ fluorescence $(F)$ and photosynthetic available radiation (PAR) profiles allowed to analyze Chl- $a$ profile types. The upper mixed layer (UML) thickness varied widely (5-20 $\mathrm{m}$ ) between stations. In case an appearance of the thermocline (TC) within euphotic zone Chl- $a$ vertical distribution was characterized by unimodal profile with deep chlorophyll a maximum (DCM) in the layer below TC (Fig. 1). The DCM was located near the bottom of euphotic zone (at 1\%PAR). The Chl- $a$ in the DCM was in 1.5-6 times higher in comparison to surface layer. The DCM formation is likely to result of an increasing of intracellular chlorophyll a concentration in comparison with the surface phytoplankton due to phytoplankton acclimation/adaptation to the environmental factors - mainly to irradiance (Falkowski and Raven, 2007). At a few stations bimodal Chl- $a$ profile was observed: second maximum was appeared in TC layer. Deepening of the TC down to the bottom of euphotic zone resulted in relatively homogeneous Chl- $a$ distribution within euphotic layer (Fig. 1).

It was shown that water stratification effected on light absorbance capacity of phytoplankton. In the deeper layer of euphotic zone (below the TC) shape of the $a_{p h}(\lambda)$ spectrum has a specific feature - a local maximum at 550-570 $\mathrm{nm}$ in comparison to the upper layer absorption spectra (Fig. 2). Light absorbance in the spectral band $550-570 \mathrm{~nm}$ is associated with phycoerythrin (PE). The PE-sign became more marked on $a_{p h}(\lambda)$ spectra at depth near the bottom of euphotic zone, where with PAR is low (1-0.1\% of the PAR incident on the lake surface). The appearance of the PE-sign reflects increasing of PE share in total amount of phytoplankton pigments in water, which is associated with increasing of PE-containing species in phytoplankton community. The PE-containing species are likely to be cyanobacteria and eukaryotic algae (Phylum Cryptophyta) with light absorbance bands at $\sim 500, \sim 550$ and $\sim 566 \mathrm{~nm}$ (Moore et al., 1995; Novarino, 2003; Six et al., 2007; Heidenreich and Richardson, 2020). The revealed significant depthdependent variability in $a_{p h}(\lambda)$ was associated with changes in phytoplankton species composition caused by adaptation of the phytoplankton community to environment, particular to spectral features of downwelling irradiance.

The NAP and CDOM absorption spectra were described by exponential function. The NAP absorption was correlated with phytoplankton absorption: the NAP contribution to particulate light absorption at $\sim 440 \mathrm{~nm}$ was $\sim 20 \%$ on averaged. The NAP spectra slope coefficient $\left(\mathrm{S}_{\mathrm{NAP}}\right)$ was slightly variable and equal to $0.010 \mathrm{~nm}^{-1}$ on averaged, which agreed well with the results from other water areas (Bricaud et al., 1998; Babin et al., 2003; Zhang et al., 2007; Churilova et al., 2017; 2018; Shi et al., 2017;). The CDOM spectra slope coefficient $\left(\mathrm{S}_{\mathrm{CDOM}}\right)$ was $0.018 \mathrm{~nm}^{-1}$ on averaged. The analysis of $a_{C D O M}(440)$ and $\mathrm{S}_{\mathrm{CDOM}}$ variability revealed the relationship between them: the higher values of $\mathrm{S}_{\mathrm{CDOM}}$ corresponding to the lower values of $a_{C D O M}(440)$ resulted of photo-destruction of high molecular weight compounds to low molecular weight compounds of CDOM (Helms et al., 2008). This type of relationship was in a good agreement with the results observed in the other water areas (Babin et al., 2003; Matsuoka et al., 2012; Churilova et al., 2017; Shi et al., 2017). Parameterization of light absorption by NAP and CDOM revealed no differences between July 2018 and September 2019.

The absorption budget was assessed at the different wavelengths corresponding to satellite 

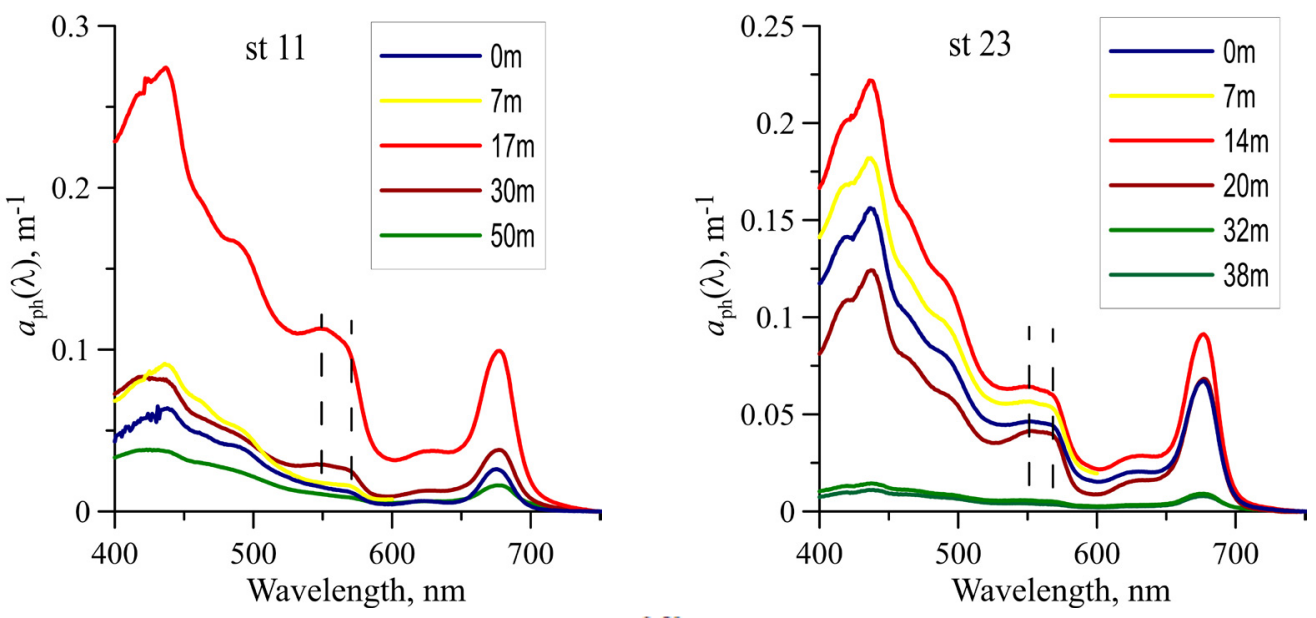

Fig. 2. Phytoplankton light absorption coefficients $\left(a_{p h}(\lambda)\right)$ at different depths at particular stations in Lake Baikal in September 2019 (dashed black lines are corresponding to 550 and $565 \mathrm{~nm}$ ).

scanners spectral bands. At the $\sim 440 \mathrm{~nm}$ (corresponding to the blue maximum of phytoplankton light absorption spectra) relative contribution of the phytoplankton pigments, NAP and CDOM to total light absorption varied significantly (up to order) between regions of Lake Baikal. The budget at $440 \mathrm{~nm}$ showed that the CDOM was the main optically active component, which provided $\sim 50 \%$ contribution to total absorption on averaged over Lake Baikal surface. The mean contribution of phytoplankton pigments and NAP to absorption budget at $440 \mathrm{~nm}$ was $\sim 38$ and $\sim 12 \%$, correspondingly, without statically reliable difference between years.

\section{Conclusions}

The obtained new data on variability of spectral light absorption coefficients by phytoplankton, particles and dissolved organic matter, their relation to chlorophyll $a$ concentration will be used for analysis of photosynthetic characteristics of phytoplankton, for development of spectral models of downwelling irradiance and primary production with application for remote sensing.

\section{Acknowledgments}

The authors are thankful to crews of $\mathrm{RV}$ Vereshagin and RV Titov for the help during the sampling. This research was performed in the framework of the state assignment, Russia (theme No. AAAA-A19-119061190081-9).

\section{References}

Babin M., Stramski D., Ferrari G.M. et al. 2003. Variations in the light absorption coefficients of phytoplankton, nonalgal particles, and dissolved organic matter in coastal waters around Europe. Journal of Geophysical Research 108. DOI: 10.1029/2001JC000882

Boss E., D'Sa E.J., Freeman S. et al. 2018. Ocean optics and biogeochemistry protocols for satellite ocean colour sensor validation. Vol. 1. Inherent optical property measurements and protocols: absorption coefficient. In: Neeley A.R.,
Mannino A. (Eds.). Dartmouth: IOCCG.

Bricaud A., Morel A., Babin M. et al. 1998. Variations of light absorption by suspended particles with the chlorophyll a concentration in oceanic (case 1) waters: Analysis and implications for bio-optical models. Journal of Geophysical Research 103. DOI: 10.1029/98JC02712

Churilova T., Moiseeva N., Efimova T. et al. 2017. Annual variability in light absorption by particles and colored dissolved organic matter in coastal waters of Crimea (the Black Sea). Proceedings of SPIE: 23rd International Symposium on Atmospheric and Ocean Optics: Atmospheric Physics 10466. DOI: $10.1117 / 12.2288339$

Churilova T., Efimova T., Moiseeva T. et al. 2018. Light absorption by phytoplankton, non-algal particles and colored dissolved organic matter in the Sea of Azov in January and April 2016. Proceedings of SPIE: 24th International Symposium on Atmospheric and Ocean Optics: Atmospheric Physics 10833. DOI: 10.1117/12.2505415

Falkowski P.G., Raven J.A. 2007. Aquatic photosynthesis. Princeton and Oxford: Princeton University Press.

Heidenreich K.M., Richardson T.L. 2020. Photopigment, absorption, and growth responses of marine cryptophytes to varying spectral irradiance. Journal of Phycology 56: 507-520. DOI: 10.1111/jpy.12962

Helms J.R., Stubbins A., Ritchie J.D. et al. 2008. Absorption spectral slopes and slope ratios as indicators of molecular weight, sources, and photobleaching of chromophoric dissolved organic matter. Limnology and Oceanography 53: 955-969. DOI: 10.4319/lo.2008.53.3.0955

Hill D.R.A., Rowan K.S. 1989. The biliproteins of the Cryptophyceae. Phycologia 28: 455-463. DOI: 10.2216/ i0031-8884-28-4-455.1

Jeffrey S.W., Humphrey G.F. 1975. New spectrophotometric equations for determining chlorophylls $a$, $b, c 1$ and $c 2$ in higher plants, algae and natural phytoplankton. Biochemie und Physiologie der Pflanzen [Plant Biochemistry and Physiology] 167: 191-194.

Matsuoka A., Bricaud A., Benner R. et al. 2012. Tracing the transport of colored dissolved organic matter in water masses of the Southern Beaufort Sea: relationship with hydrographic characteristics. Biogeosciences 9: 925-940. DOI: $10.5194 /$ bg-9-925-2012

Mitchell B.G. 1990. Algorithms for determining the absorption coefficient of aquatic particulates using the quantitative filter technique (QFT). Proceedings of SPIE: Ocean Optics X 1302: 137-148. DOI: 10.1117/12.21440

Moore L.R., Georicke R., Chisholm S.W.1995. Comparative physiology of Synechococcus and Prochlorococcus: influence of light and temperature on growth, pigments, fluorescence and 
absorptive properties. Marine Ecology Progress Series 116: 259-275. DOI: 10.3354/meps116259

Novarino G. 2003. A companion to the identification of cryptomonad flagellates (Cryptophyceae = Cryptomonadea). Hydrobiologia 502: 225-270. DOI: 10.1023/B:HYDR.000000 4284.12535.25

Shi L., Mao Z., Wu J. et al. 2017. Variations in spectral absorption properties of phytoplankton, non-algal particles and chromophoric dissolved organic matter in Lake Qiandaohu. Water 9. DOI: 10.3390/w9050352

Six C., Thomas J.-C., Garczarek L. et al. 2007. Diversity and evolution of phycobilisomes in marine Synechococcus spp.: a comparative genomics study. Genome Biology 8. DOI: 10.1186/gb-2007-8-12-r259

Tassan S., Ferrari G. 1995. An alternative approach to absorption measurements of aquatic particles retained on filters. Limnology and Oceanography 40: 1358-1368. DOI: 10.4319/lo.1995.40.8.1358

Zhang Y., Zhang B., Wang X. et al. 2007. A study of absorption characteristics of chromophoric dissolved organic matter and particles in Lake Taihu, China. Hydrobiologia 592: 105-120. DOI: 10.1007/s10750-007-0724-4 